\title{
Application of the vibration method for damage identification of a beam with a variable cross- sectional area
}

\author{
Izabela Zamorska ${ }^{1 *}$, Dawid Cekus ${ }^{1}$, Mateusz Miara ${ }^{1}$ \\ ${ }^{1}$ Czestochowa University of Technology, Faculty of Mechanical Engineering and Computer Science, \\ Czestochowa, Poland
}

\begin{abstract}
The subject of the paper is an application of the non-destructive vibration method for identifying the location of two cracks occurring in a beam. The vibration method is based on knowledge of a certain number of vibration frequencies of an undamaged element and the knowledge of the same number of vibration frequencies of an element with a defect. The analyzed beam, with a variable cross-sectional area, has been described according to the Bernoulli-Euler theory. To determine the values of free vibration frequencies the analytical solution, with the help of the Green's function method, has been used.
\end{abstract}

Keywords: Bernoulli-Euler beam, crack, Green's function, identification, nondestructive method, vibration

\section{Introduction}

The beams, whose geometry and/or material properties change along their length, are important for instance in the design of aircraft, robot arms and tall buildings, where they are used both to reduce weight or volume, and to increase strength and stability. However, in these types of objects even minor damage can cause structural failure and consequently even catastrophe. Therefore, it is very important to continuously control these elements and to detect damage as early as possible. To detect this type of damage, usually nondestructive methods (a visual method [1], a penetration method [2], a magnetic particles method [3], a radiographic method [4], an ultrasonic method [5] and a vibration method [69]) are used. If cracks appear, then the system parameters such as the rigidity, the vibration frequency or damping are subjected to change. Selection of the method is due to a number of factors, including the type of material, the size of the test element, and the type of internal or external damage.

In this paper, the vibration method has been used for identifying the location of symmetric cracks in the cantilever beam with a variable cross-sectional area. The vibration method is based on knowledge of a certain number of vibration frequencies of an undamaged element and the knowledge of the same number of vibration frequencies of an element with a defect (the changes in the structure cause the changes of vibration

\footnotetext{
*Corresponding author: izabela.zamorska@im.pcz.pl

Reviewers: Robert Zalewski, Milan Sága
} 
frequencies). On this basis, the normalization factors are determined, and then threedimensional graphs are created to plot contour lines to identify the crack. The number of searched parameters of one or more defects depends on the number of known frequencies. In the case of three-dimensional graphs (knowledge of the first three vibration frequencies), it is possible to identify two parameters of one damage (e.g. position and depth of gap [9]) or, as will be shown in this paper, one parameter (position of defects) of two cracks. The Green's function method $[9-11,13]$ was used to determine the vibration frequencies of the analyzed beam described according to the Bernoulli-Euler theory.

\section{Formulation and solution of the free vibration problem of the beam with a variable cross-sectional area}

In the paper, the cantilever beam with a varying cross sectional-area along the length and with two symmetrical cracks (Figure 1) has been analyzed.

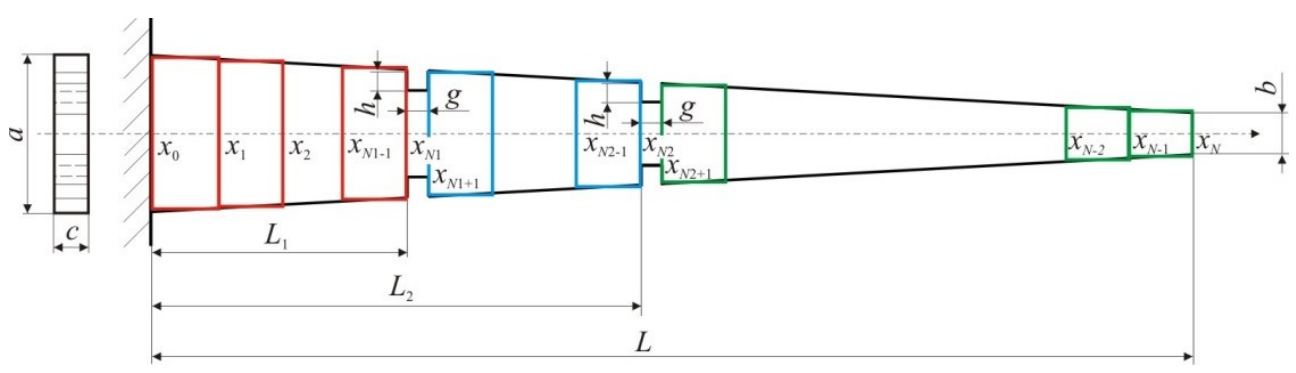

Fig. 1. A scheme of the system under study

Because the identification damage process using the frequency method requires the knowledge of vibration frequencies of an undamaged element and the same number of vibration frequencies of an element with a defect, the analytical formulation and solution of the problem have been carried out.

Each $N$ beam's segment (length $\Delta_{i}=x_{i}-x_{i-1}$, where $i=1, \ldots, N, x_{0}=0, x_{N}=L$ ) have the same physical properties and geometrical parameters.

The governing differential equation of motion of $i$-th system's segment is:

$$
\bar{\Lambda}_{i}\left[Z_{i}(x, t)\right]=-\bar{S}_{i-1}(t) \delta\left(x-x_{i-1}\right)+\bar{S}_{i}(t) \delta\left(x-x_{i}\right)+\bar{M}_{i-1}(t) \delta^{\prime}\left(x-x_{i-1}\right)-\bar{M}_{i}(t) \delta^{\prime}\left(x-x_{i}\right),
$$

where: $\bar{\Lambda}_{i}=E I_{i} \frac{\partial^{4}}{\partial x^{4}}+\rho A_{i} \frac{\partial^{2}}{\partial t^{2}}$ is the linear differential operator, $Z_{i}(x, t)$ is the transverse displacement, $E I_{i}$ is the flexural rigidity and $\rho A_{i}$ is the mass per unit length. Moreover, functions $\bar{S}_{i}$ and $\bar{M}_{i}$ are the shear force and the bending moment acting on the right end of $i$-th segment, $\delta()$ and $\delta^{\prime}()$ are the Dirac's delta and its derivative (the doublet function [12]). The functions $Z_{1}$ and $Z_{N}$ satisfy homogeneous boundary conditions:

$$
\overline{\mathbf{B}}_{0}\left[\left.Z_{1}(x, t)\right|_{x=0}=0, \quad \overline{\mathbf{B}}_{1}\left[Z_{N}(x, t)\right]_{x=L}=0\right.
$$

and the continuity conditions at the dividing points $x_{i}$ :

$$
\left.Z_{i}(x, t)\right|_{x=x_{i}}=\left.Z_{i+1}(x, t)\right|_{x=x_{i}},\left.\quad Z_{i, x}(x, t)\right|_{x=x_{i}}=\left.Z_{i+1, x}(x, t)\right|_{x=x_{i}}, \quad i=1, \ldots, N-1 .
$$


Assuming free vibration of the beam, we can separate variables: $Z_{i}(x, t)=z_{i}(x) e^{j \omega t}$, $\bar{S}_{i}(t)=S_{i} e^{j \omega t}, \bar{M}_{i}(t)=M_{i} e^{j \omega t}$, where $j^{2}=-1$ and $\omega$ is the free vibration frequency. Next, introducing parameters: $\Omega_{i}^{4}=\frac{\rho A_{i}}{E I_{i}} \omega^{2}, A_{i}=A\left(x_{i}^{*}\right), I_{i}=I\left(x_{i}^{*}\right)$ for $x_{i}^{*}=\frac{x_{i}-x_{i-1}}{2}, s_{i}=\frac{S_{i}}{E I_{i}}$, $m_{i}=\frac{M_{i}}{E I_{i}}$ and operator $\Lambda_{i}=\frac{d^{4}}{d x^{4}}-\Omega_{i}^{4}$, the equation (1) and conditions (2), (3) may be written as follows:

$$
\begin{gathered}
\Lambda_{i}\left[z_{i}(x)\right]=-S_{i-1} \delta\left(x-x_{i-1}\right)+s_{i} \delta\left(x-x_{i}\right)+m_{i-1} \delta^{\prime}\left(x-x_{i-1}\right)-m_{i} \delta^{\prime}\left(x-x_{i}\right), \\
\mathbf{B}_{0}\left[z_{1}(x)\right]_{x=0}=0, \quad \mathbf{B}_{1}\left[z_{N}(x)\right]_{x=L}=0, \\
\left.z_{i}(x)\right|_{x=x_{i}}=\left.z_{i+1}(x)\right|_{x=x_{i}},\left.\quad z_{i, x}(x)\right|_{x=x_{i}}=\left.z_{i+1, x}(x)\right|_{x=x_{i}}, \quad i=1, \ldots, N-1 .
\end{gathered}
$$

The solution of the problem (4-6) can be obtained with the help of the Green's function method $[9-11,13]$.

The Green's functions of the operators $\boldsymbol{\Lambda}_{i}$ satisfy the non-homogeneous equations $\boldsymbol{\Lambda}_{i}\left[G_{i}\right]=\delta(x-\xi)$ and the same boundary and continuous conditions as the transverse displacement functions $z_{i}$. Functions $G_{i}$ can be written as the sum:

$$
G_{i}(x, \xi)=\sum_{k=1}^{4} C_{i k} y_{k}(x)+\left(2 \Omega_{i}^{3}\right)^{-1}\left[y_{4}(x-\xi)-y_{2}(y-\xi)\right]
$$

where: $\quad y_{1}(x)=\cos (\Omega x), \quad y_{2}(x)=\sin (\Omega x), \quad y_{3}(x)=\cosh (\Omega x), \quad y_{4}(x)=\sinh (\Omega x) \quad$ constitute a system of fundamental solutions to the homogeneous equation $\Lambda_{i}\left[G_{i}\right]=0$ and coefficients $C_{i k}$ are obtained from the boundary conditions corresponding to the $i$-th segment of the beam.

For a clamped-free beam function $G_{1}$ satisfies conditions corresponding with a clamped left end and free a right end. In that case we can present coefficients $C_{1 k}$ as follows:

$$
\begin{gathered}
C_{11}=\left(W_{1}\right)^{-1}\left[\alpha_{21} \gamma_{1}\left(x_{1}, \xi\right)-\beta_{21} \gamma_{2}\left(x_{1}, \xi\right)\right], \\
C_{12}=\left(W_{1}\right)^{-1}\left[\alpha_{11} \gamma_{2}\left(x_{1}, \xi\right)+\beta_{11} \gamma_{1}\left(x_{1}, \xi\right)\right], \\
C_{13}=-a_{1}(0) C_{11}-b_{2}(0) C_{12} \\
C_{14}=b_{1}(0) C_{11}-a_{2}(0) C_{12} .
\end{gathered}
$$

The functions $G_{2}, \ldots, G_{N}$ satisfy conditions corresponding with free-free ends. In that case constants $C_{i k}(i=2, \ldots, N)$ are:

$$
\begin{gathered}
C_{i 1}=\left(W_{2}\right)^{-1}\left[\alpha_{22} \gamma_{1}\left(x_{i}, \xi\right)-\beta_{22} \gamma_{2}\left(x_{i}, \xi\right)\right], \\
C_{i 2}=\left(W_{2}\right)^{-1}\left[\alpha_{12} \gamma_{2}\left(x_{i}, \xi\right)+\beta_{12} \gamma_{1}\left(x_{i}, \xi\right)\right], \\
C_{i 3}=a_{1}\left(x_{i-1}\right) C_{i 1}+b_{2}\left(x_{i-1}\right) C_{i 2},
\end{gathered}
$$




$$
C_{i 4}=-b_{1}\left(x_{i-1}\right) C_{11}+a_{2}\left(x_{i-1}\right) C_{i 2} .
$$

The designations used in the formulas are as follows:

$$
\begin{gathered}
a_{s}(x)=y_{1}(x) y_{3}(x)-(-1)^{s} y_{2}(x) y_{4}(x), \\
b_{s}(x)=y_{2}(x) y_{3}(x)-(-1)^{s} y_{1}(x) y_{4}(x), \\
\alpha_{p s}=\alpha_{p s}\left(x_{i-1}, x_{i}\right)=a_{s}\left(x_{i}\right)+(-1)^{p} a_{s}\left(x_{i-1}\right), \\
\beta_{p s}=\beta_{p s}\left(x_{i-1}, x_{i}\right)=b_{s}\left(x_{i}\right)+(-1)^{p} b_{s}\left(x_{i-1}\right), \\
W_{s}=\alpha_{1 s} \alpha_{2 s}+\beta_{1 s} \beta_{2 s}, \quad p, s=1,2, \\
\gamma_{1}(x, \xi)=\frac{1}{2 \Omega_{i}^{3}}\left\{\left[y_{2}(x-\xi)+y_{4}(x-\xi)\right] y_{3}(x)-\left[y_{1}(x-\xi)+y_{3}(x-\xi)\right] y_{4}(x)\right\}, \\
\gamma_{2}(x, \xi)=\frac{1}{2 \Omega_{i}^{3}}\left\{\left[y_{1}(x-\xi)+y_{3}(x-\xi)\right] y_{3}(x)-\left[y_{2}(x-\xi)+y_{4}(x-\xi)\right] y_{4}(x)\right\} .
\end{gathered}
$$

If the Green's function is known, we can determine the solution of (4) in the form [9-11, 13]:

$$
z_{i}(x)=-\mu_{i-1} s_{i-1} G_{i}\left(x, x_{i-1}\right)+s_{i} G_{i}\left(x, x_{i}\right)+\mu_{i-1} m_{i-1} G_{i, \xi}\left(x, x_{i-1}\right)-m_{i} G_{i, \xi}\left(x, x_{i}\right),
$$

where: $\mu_{i-1}=\frac{E I_{i-1}}{E I_{i}}$ are flexural rigidity distribution coefficients and $s_{0}=m_{0}=s_{N}=m_{N}=0$. Substituting solution (11) into continuity conditions (6) and introducing functions:

$$
P_{i}(x, \xi)=\mu_{i-1} G_{i}(x, \xi), \quad Q_{i}(x, \xi)=G_{i}(x, \xi)+\mu_{i} G_{i+1}(x, \xi), \quad R_{i}(x, \xi)=G_{i+1}(x, \xi),
$$

we obtain a linear set of $2 N-2$ equations with unknown parameters $s_{i}, m_{i}(i=2, \ldots, N-1)$. In a matrix form, it is given as follows:

$$
\mathbf{A}(\omega) \mathbf{X}=\mathbf{0}
$$

where a non-zero elements of a main matrix $\mathbf{A}$ are given below:

$$
\begin{aligned}
a_{1,1}=Q_{1}\left(x_{1}, x_{1}\right), & a_{1,2}=-R_{1}\left(x_{1}, x_{2}\right), \\
a_{2,1}=-Q_{1, x}\left(x_{1}, x_{1}\right), & a_{2,2}=R_{1, x}\left(x_{1}, x_{2}\right), \\
a_{1, N}=-Q_{1, \xi}\left(x_{1}, x_{1}\right), & a_{1, N+1}=R_{1, \xi}\left(x_{1}, x_{2}\right), \\
a_{2, N}=-Q_{1, \xi x}\left(x_{1}, x_{1}\right), & a_{2, N+1}=R_{1, \xi x}\left(x_{1}, x_{2}\right), \\
a_{2 i-1, i-1}=-P_{i}\left(x_{i}, x_{i-1}\right), & a_{2 i-1, i}=Q_{i}\left(x_{i}, x_{i}\right), \quad a_{2 i-1, i+1}=-R_{i}\left(x_{i}, x_{i+1}\right),
\end{aligned}
$$




$$
\begin{gathered}
a_{2 i, i-1}=P_{i, x}\left(x_{i}, x_{i-1}\right), \quad a_{2 i, i}=-Q_{i, x}\left(x_{i}, x_{i}\right), \quad a_{2 i, i+1}=R_{i, x}\left(x_{i}, x_{i+1}\right), \\
a_{2 i-1, N+i-2}=P_{i, \xi}\left(x_{i}, x_{i-1}\right), a_{2 i-1, N+i-1}=-Q_{i, \xi}\left(x_{i}, x_{i}\right), \quad a_{2 i-1, N+i}=R_{i, \xi}\left(x_{i}, x_{i+1}\right), \\
a_{2 i, N+i-2}=P_{i, \xi x}\left(x_{i}, x_{i-1}\right), a_{2 i, N+i-1}=-Q_{i, \xi x}\left(x_{i}, x_{i}\right), \quad a_{2 i, N+i}=R_{i, \xi x}\left(x_{i}, x_{i+1}\right), \\
a_{2 N-3, N-2}=-P_{N-1}\left(x_{N-1}, x_{N-2}\right), a_{2 N-3, N-1}=Q_{N-1}\left(x_{N-1}, x_{N-1}\right), \\
a_{2 N-2, N-2}=P_{N-1, x}\left(x_{N-1}, x_{N-2}\right), \quad a_{2 N-2, N-1}=-Q_{N-1, x}\left(x_{N-1}, x_{N-1}\right), \\
a_{2 N-3,2 N-3}=P_{N-1, \xi}\left(x_{N-1}, x_{N-2}\right), a_{2 N-3,2 N-2}=-Q_{N-1, \xi}\left(x_{N-1}, x_{N-1}\right), \\
a_{2 N-2, N-3}=P_{n-1, \xi x}\left(x_{N-1}, x_{N-2}\right), a_{2 N-2,2 N-2}=-Q_{N-1, \xi x}\left(x_{N-1}, x_{N-1}\right) .
\end{gathered}
$$

The frequency equation $\operatorname{det} \mathbf{A}(\omega)=0$ is solved numerically with respect to the frequency $\omega$. The mode shapes corresponding to the multi-stepped beam's frequency are in the form (11), where unknown vector $\mathbf{X}=\left[\begin{array}{llllll}s_{1} & \ldots & s_{N-1} & m_{1} & \ldots & m_{N-1}\end{array}\right]^{T}$ is determined from (13), assuming the value of one of the coefficients $s_{i}, m_{i}$ (for example $m_{N-1}=1$ ).

\section{Sample numerical results of identification of the cracks' position}

Using the presented model, the algorithm and computer program that enable the determination of the free vibration frequencies of the cantilever beam with a variable cross-sectional area have been worked out.

The exemplary results of numerical calculations illustrate the identification of distance $\left(L_{1}, L_{2}\right)$ of cracks from the attachment. The following values of parameters have been accepted: $a=75 \mathrm{~mm}, b=20 \mathrm{~mm}, c=5 \mathrm{~mm}, g=1 \mathrm{~mm}, h=10 \mathrm{~mm}$ and $L=500 \mathrm{~mm}$.

On the basis of the determined first three natural frequencies, the normalization process has been performed. In this case, the normalization is defined as the ratio of the frequency of the damaged beam $\left(\omega_{u}\right)$ to the frequency of the beam without defect $\left(\omega_{n}\right)$ :

$$
\lambda=\frac{\omega_{u}}{\omega_{n}}
$$

Based on the normalization factors, the three-dimensional graphs are created. In Figures $2-4$, the changes of the values of the first three normalized vibration frequencies depending on the location of two cracks and sample contour lines corresponding to them (used later in the identification process) are shown. On the basis of three-dimensional graphs, the individual contour lines for each examined frequency having the same parameters of the damage must be plotted (Figs. 5-7). As an example, in Figure 8, the contour lines for the cracks located at the beginning of the beam (first) and close to the free end of the beam (second) were plotted. 


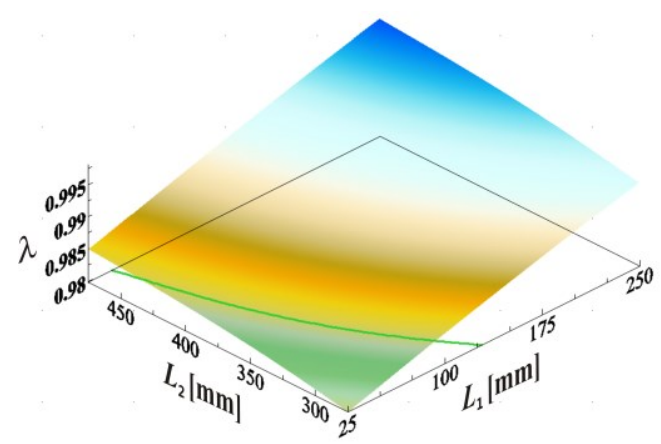

Fig. 2. The first normalized vibration frequency depending on the location of two cracks

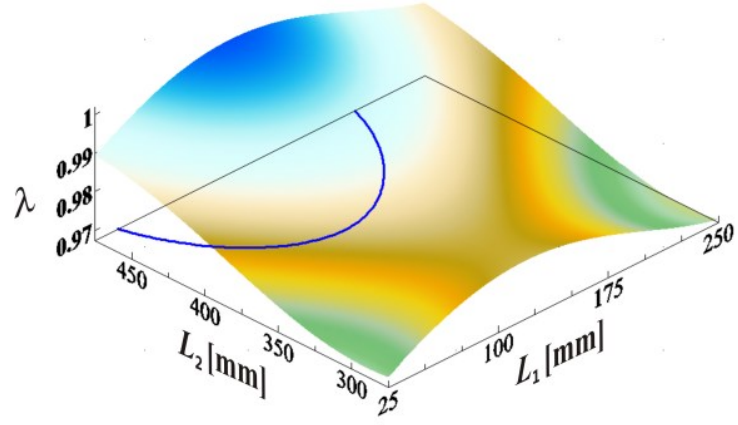

Fig. 3. The second normalized vibration frequency depending on the location of two cracks

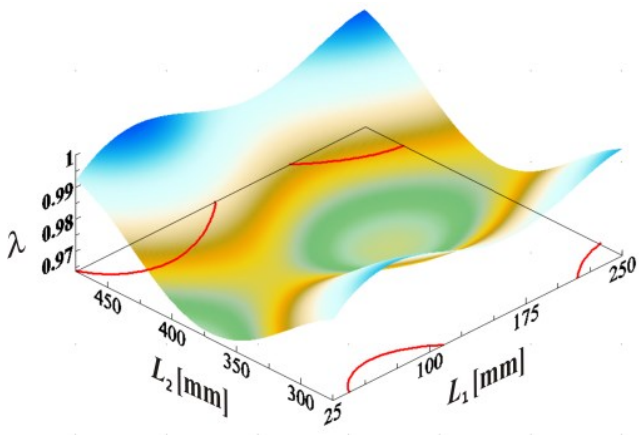

Fig. 4. The third normalized vibration frequency depending on the location of two cracks 


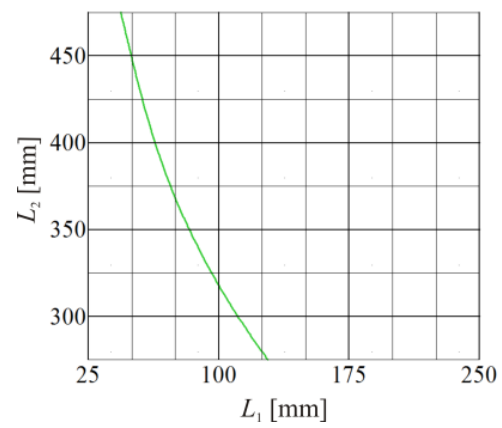

Fig. 5. Contour line for the first normalized vibration frequency

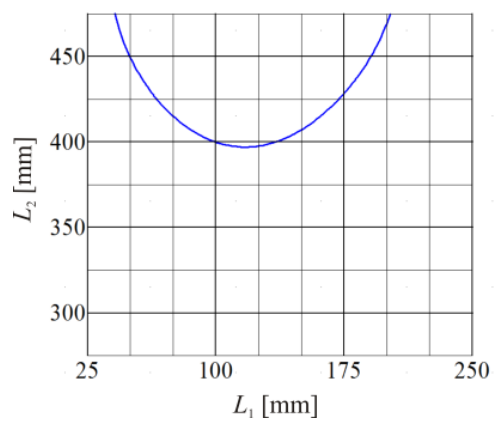

Fig. 6. Contour lines for the second normalized vibration frequency

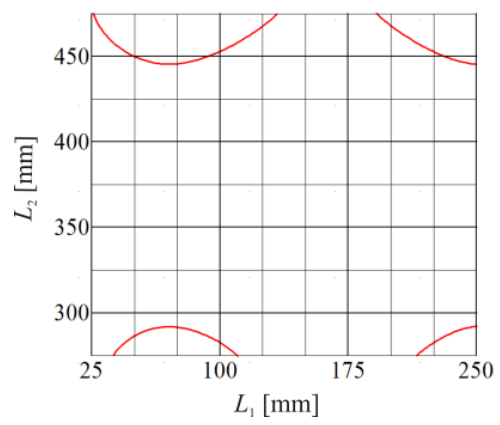

Fig. 7. Contour lines for the third normalized vibration frequency

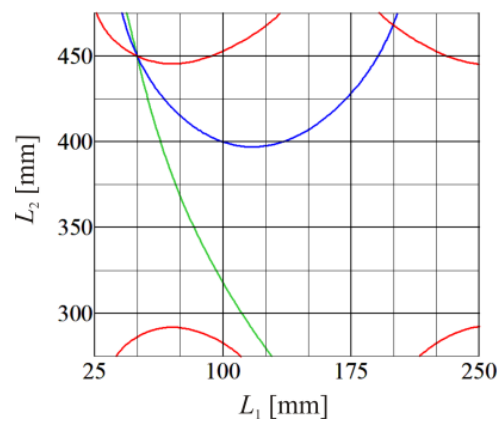

Fig. 8. The identified position of cracks 
As a result of the intersection of the contour lines (Figure 8), the point defining the places where the cracks are located was determined. The distances of the cracks from the attachment obtained in the identification process $\left(L_{1 d}=49.7 \mathrm{~mm}\right.$ and $\left.L_{2 d}=450.2 \mathrm{~mm}\right)$ practically coincide with the values $\left(L_{1 a}=50 \mathrm{~mm}, L_{2 a}=450 \mathrm{~mm}\right)$ assumed during the numerical simulations. To verify the accuracy of the discussed identification process, the cases specified in Table 1 were additionally executed. The relative error defines the difference between the assumed positions of cracks $\left(L_{1 a}, L_{2 a}\right)$ and the values calculated in the identification process $\left(L_{1 d}, L_{2 d}\right)$ :

$$
\Delta L=\left(\frac{\left|L_{1 a}-L_{1 d}\right|}{2 L_{1 d}}+\frac{\left|L_{2 a}-L_{2 d}\right|}{2 L_{2 d}}\right) \cdot 100 \%
$$

Table 1. Positions of cracks obtained with the help of the non-destructive vibration method

\begin{tabular}{|c|c|c|c|c|}
\hline \multicolumn{2}{|c|}{ Assumed positions of cracks } & \multicolumn{2}{|c|}{ Determined positions of cracks } & $\begin{array}{c}\text { The relative } \\
\text { error } \Delta L[\%]\end{array}$ \\
\cline { 1 - 3 }$L_{1 a}[\mathrm{~mm}]$ & $L_{2 a}[\mathrm{~mm}]$ & $L_{1 d}[\mathrm{~mm}]$ & $L_{2 d}[\mathrm{~mm}]$ & 0.54 \\
\hline 50 & 300 & 49.5 & 299.8 & 1.14 \\
\hline 125 & 300 & 123 & 302 & 0.15 \\
\hline 225 & 300 & 224.7 & 299.5 & 5.58 \\
\hline 50 & 375 & 45 & 375.2 & 2.85 \\
\hline 125 & 375 & 132 & 376.5 & 0.81 \\
\hline 225 & 375 & 222.6 & 373 & 0.32 \\
\hline 50 & 450 & 49.7 & 450.2 & 0.29 \\
\hline 125 & 450 & 125.5 & 450.8 & 0.23 \\
\hline 225 & 450 & 225.8 & 450.5 & \\
\hline
\end{tabular}

Based on the results compiled in Table 1, it can be seen that the relative error in most cases does not exceed 3\%. The largest value of the relative error is for damages occurring at points $L_{1 a}=50 \mathrm{~mm}$ and $L_{2 a}=375 \mathrm{~mm}$. The smallest relative error $(0.15 \%)$ is the case where the cracks are closest to each other in relation to all considered instances. Moreover, for $L_{2}=375 \mathrm{~mm}$ or $L_{2}=450 \mathrm{~mm}$ and with an increase $L_{1}$ the error decreases.

\section{Conclusions}

In the present work, the identification of the location of two symmetrical cracks occurring in the cantilever beam with a variable cross-sectional area has been done. For identification, the non-destructive vibration method has been applied. This method requires knowledge of the frequencies of the system without and with the damage. The solution of the free vibration problem of the beam described according to the Bernoulli-Euler theory has been obtained with the help of Green's functions.

In the computational models, a rigid restraint has been used. However, this type of boundary condition is impossible to achieve in real objects. Therefore, mathematical models should be experimentally verified. In the case when the system response diverges from the theoretical results, then an identification of the model must be performed [14].

Although in this study only exemplary numerical research has been carried out, this method can be successfully used for the identification of damage of real objects. Identifying structure damage at an early stage has a great influence on the repair cost and has a significant impact on safety. 


\section{References}

1. T. Yamaguchi, S. Hashimoto, Fast crack detection method for large-size concrete surface images using percolation-based image processing. Machine Vision and Applications 21 (5), 797-809 (2010).

2. H. Miyazaki, Y. Nomura, H. Sugai, M. Iijima, S. Inasawa, H. Kamiya, Liquid penetration as a simple detection method for structural differences in particulate films prepared from slurries. Powder Technology 303, 59-67 (2016)

3. X. Li, H. Jiang, G. Yin, Detection of surface crack defects on ferrite magnetic tile, Journal of Sound and Vibration 375 (4), 200-216 (2016)

4. N. Boaretto, T.M. Centeno, Automated detection of welding defects in pipelines from radiographic images DWDI. NDT \& E International, http://dx.doi.org/10.1016/j.ndteint.2016.11.003

5. S. Mezil, N. Chigarev, V. Tournat, V. Gusev, Evaluation of crack parameters by a nonlinear frequency-mixing laser ultrasonics method. Ultrasonics 69, 225-235 (2016)

6. G.M. Owolabi, A.S.J. Swamidas, R. Seshadri, Crack detection in beams using changes in frequencies and amplitudes of frequency response functions. Journal of Sound and Vibration 265, 1-22 (2003)

7. P. Yamuna, K. Sambasivarao, Vibration Analysis of Beam With Varying Crack Location. International Journal of Engineering Research and General Science 2 (6), ISSN 2091-2730, (2014)

8. K. Sokół, Linear and nonlinear vibrations of a column with an internal crack. J. Eng. Mech 140 (5), 04014021, http://dx.doi.org/10.1061/(ASCE)EM.1943-7889.0000719 (2014)

9. D. Cekus, M. Miara, I. Zamorska, Damage identification of a beam with a variable cross-sectional area. Journal of Mathematics and Computational Mechanics 15 (4), 23 32 (2016)

10. S. Kukla, I. Zamojska, Frequency analysis of axially loaded stepped beams by Green's function method. Journal of Sound and Vibration 300, 1034-1041 (2007)

11. S. Kukla, Dynamiczne funkcje Greena w analizie drgań własnych ciagłych i dyskretnociagtych układów mechanicznych. seria Monografie 64, Wydawnictwo Politechniki Częstochowskiej (1999)

12. J. Mikusiński, R. Sikorski, Elementarna teoria dystrybucji. PWN, Warszawa (1964)

13. J. Lee, L.A. Bergman, The vibration of stepped beams and rectangular plates by an elemental dynamic flexibility method. Journal of Sound and Vibration 171, 617-640 (1994)

14. D. Cekus, P. Waryś: Identification of parameters of discrete-continuous models. AIP Conf. Proc. 1648 , 850055 (2015) 